\title{
Re-engineering rural farmers for sustainable agricultural food production for diversifying economy in ebonyi state, Nigeria
}

\author{
E. I. OGBA AND J. U. NDEM
}

\begin{abstract}
The gradual decline and short fallen in agricultural food production as demanded by large population in Nigeria and subsequent failure on the price of crude oil prompted this study to diversify the Nigeria economy, through agricultural production by Reengineering rural farmers. The population of the study was 402 rural farmers in the three agricultural zones in Ebonyi State. 195 rural farmers were randomly selected, as the sample size for the study. The instrument for data collection was Re-engineering rural farmers for sustainable agricultural food production for diversifying, Nigeria economy questionnaire (RRFSAFPDNEQ).The instrument was validated by 3 experts two in agricultural education unit in Department of Technology and Vocational Education,one in measurementand Evaluation in Department of Science Education,in Ebonyi State University, Abakaliki.Crownback alpha, reliability co-efficient was used to test the internal consistency of the Instrument, which yielded 0.86 . The instrument was administered to the respondents with the help of 3 research assistant, one in each agricultural zone, mean and standard deviation was used to answer the research questions. Findings of the studyreveals (1) That, ecological factors favours agricultural crop production in the state. (2) That machinaries for agricultural food crop mechanization are not available for farmers to use in farming activities. (3)That farmer's sources for financing, their, farm is mainly on personal saves.Among the recommendation made was that farmers need to be assisted in the areas of irrigation to encourage them in dry season farming.
\end{abstract}

KEY WORDS : Re-engineer, Rural farmer, Agricultural food production, Diversifying, Economy

How to cite this Article : Ogba, E.I. and Ndem, J.U. (2017). Re-engineering rural farmers for sustainable agricultural food production for diversifying economy in ebonyi state, Nigeria. Engg. \& Tech. in India, 8 (1\&2) : 74-79; DOI : 10.15740/HAS/ETI/8.1\&2/ 74-79. 